\title{
Alterações das propriedades químicas de um latossolo vermelho distroférrico submetido a tratamentos com resíduos orgânicos
}

\section{Chemical properties changes of a typical clayey oxisol submitted to different treatments of organic residues}

\author{
Osmar Rodrigues Brito ${ }^{1 *}$; Pedro Rodolfo S. Vendrame ${ }^{2}$; Rafael Mizubuti Brito ${ }^{3}$
}

\section{Resumo}

Nos últimos anos, tem crescido gradualmente o emprego de adubos orgânicos na agricultura brasileira. Com o objetivo de avaliar as alterações nas propriedades químicas de um Latossolo Vermelho distroférrico, em função da aplicação de diferentes resíduos orgânicos, foi instalado um experimento na Fazenda Escola da Universidade Estadual de Londrina, Londrina-PR. Foram testados os seguintes tratamentos: esterco de bovino $\left(8 \mathrm{~T} \mathrm{ha}^{-1}\right)$, esterco de poedeira $\left(3 \mathrm{~T} \mathrm{ha}^{-1}\right)$, cama de frango $\left(6 \mathrm{~T} \mathrm{ha}^{-1}\right)$, esterco de ovino $\left(6 \mathrm{~T} \mathrm{ha}^{-1}\right)$ e resíduo de silagem de sorgo $\left(8 \mathrm{~T} \mathrm{ha}^{-1}\right)$. O delineamento experimental utilizado foi em blocos casualizados, com 6 tratamentos e 3 repetições. Cada resíduo foi aplicado duas vezes, no início e aos doze meses após a instalação do experimento. Amostragens de solo foram realizadas aos 3, 6, 9, 12, 18 e 24 meses após a primeira aplicação dos resíduos. As amostras foram avaliadas quimicamente para as seguintes variáveis: $\mathrm{pH} \mathrm{em} \mathrm{CaCl}_{2}, \mathrm{H}+\mathrm{Al}$, $\mathrm{Ca}, \mathrm{Mg}, \mathrm{K}, \mathrm{P}$, matéria orgânica, $\mathrm{CTC}$ e saturação por bases $(\mathrm{V})$. Os dados obtidos foram submetidos à análise de variância e as médias foram comparadas pelo teste Tukey a 1 e 5\%. A aplicação dos resíduos orgânicos resultou em alterações das propriedades químicas e na fertilidade do solo. Para as doses testadas, destacouse o tratamento esterco de ovino, que promoveu os maiores aumentos para cálcio trocável, matéria orgânica e CTC do solo. O esterco de poedeira aumentou os teores de fósforo.

Palavras-chave: Análises químicas, estercos, nutrientes, disponibilidade

\begin{abstract}
The use of organic fertilizers in Brazilian agriculture has been increased recently. With the objective of evaluating the alterations in chemical properties of a typical clayey, oxisol, in Londrina, Londrina PR, Brazil, an experiment was conducted with the application of different organic residues. The following treatments were tested: bovine manure $\left(8 \mathrm{~T} \mathrm{ha}^{-1}\right)$, hen manure $\left(3 \mathrm{~T} \mathrm{ha}^{-1}\right)$, broiler litter $\left(6 \mathrm{~T} \mathrm{ha}^{-1}\right)$, sheep manure $\left(6 \mathrm{~T} \mathrm{ha}^{-1}\right)$ and silage residue $\left(8 \mathrm{~T} \mathrm{ha}^{-1}\right)$. The experimental design was in randomized blocks with 6 treatments and 3 replications. Each residue was applied twice, in the beginning and 12 months after the experiment installation. Soil samplings were taken at 3, 6, 9, 12, 18, and 24 months after the application of the residues. Each sample was evaluated chemically for the following variables: $\mathrm{pH}$ in $\mathrm{CaCl}_{2}, \mathrm{H}+\mathrm{Al}, \mathrm{Ca}$, $\mathrm{Mg}, \mathrm{K}, \mathrm{P}$, organic matter, $\mathrm{CEC}$ and saturation for bases $(\mathrm{V})$. In general way, the organic residues application resulted in alterations in the chemical properties of the soil. The best treatment tested was the sheep manure that promoted a larger increase of exchangeable calcium, organic matter and CEC of the studied soil. The hen manure increased the levels of soil phosphorus.

Key words: Chemical analysis, manure, nutrients, availability

1 Docente do Departamento de Agronomia /CCA -UEL. CP. 6001.CEP 86051-990. Londrina PR, e-mail: osmar@uel.br.

2 Doutorando do Programa de Pós Graduação em Agronomia. UEL, Londrina, PR

3 Acadêmico do Curso de Graduação em Agronomia, UEL, Londrina, PR

Autor para correspondência
\end{abstract}




\section{Introdução}

O emprego da adubação orgânica vem crescendo gradualmente no Brasil nos últimos anos. O uso intensivo desse tipo de adubação pode resultar em modificações profundas nas propriedades químicas e na fertilidade atual dos solos. De maneira geral, os solos agrícolas são constituídos, em grande parte, pela fração mineral e somente uma pequena porção é representada pela matéria orgânica. Segundo Brady (1989), a contribuição da matéria orgânica é menor que $5 \%$ da massa total, na maioria dos solos agrícolas.

O conteúdo de matéria orgânica dos solos merece atenção especial, pois resulta da decomposição de resíduos animais e vegetais e varia, principalmente, com as práticas de manejo adotadas em cada propriedade agrícola. Além disso, é influenciado diretamente pelas condições edafoclimáticas de cada região. Para Igue (1984) e Raij (1991), o efeito favorável da matéria orgânica nas características dos solos está relacionado à agregação das partículas e à estabilização dos agregados, o que resulta em maior porosidade, aeração e retenção de água. Ao mesmo tempo contribui para o fornecimento de nutrientes para as plantas. A decomposição da matéria orgânica nos solos tropicais ou subtropicais de climas úmidos, ocorre rapidamente, sendo que uma redução excessiva no seu teor afetará negativamente as funções química, física e biológica deste solo, redundando em diminuição na produtividade das culturas (MALAVOLTA; PIMENTEL-GOMES; ALCARDE, 2002).

Diferentes técnicas são utilizadas com a finalidade de manejar a matéria orgânica dos solos. Dentre estas, pode-se destacar a preservação dos resíduos agrícolas deixados pelas colheitas e a adição de estercos e ou resíduos agro-industriais. Estas práticas visam elevar, manter ou conservar os teores de matéria orgânica dos solos.

Embora certa fração da matéria orgânica dos estercos seja decomposta e liberada no período de um a dois anos, outra fração é transformada em húmus, que é mais estável. Sob essa forma, os elementos são liberados lentamente. Assim, os componentes do esterco, convertidos em húmus, exercerão influência nos solos de maneira persistente e duradoura (BRADY, 1989).

A quantidade de esterco e outros resíduos orgânicos a ser adicionada em determinada área depende, entre outros fatores, da composição e do teor de matéria orgânica dos referidos resíduos, classe textural e nível de fertilidade do solo, exigências nutricionais da cultura explorada e condições climáticas regionais (DURIGON et al., 2002). Em geral, os estercos de ovinos, caprinos e eqüinos apresentam menores teores de umidade do que os de bovinos e suínos. O esterco de poedeira é mais rico em nutrientes do que o de outros animais, pois estas aves normalmente se alimentam de rações concentradas (KIEHL, 1985).

Vários estudos têm demonstrado a eficiência dos resíduos orgânicos na melhoria das propriedades químicas, físicas e biológicas do solo e no aumento da produtividade das culturas. Holanda; Mielniczuk e Stammel (1982) observaram que a adição de esterco de poedeira, resultou no aumento da CTC, teores de $\mathrm{Ca}$ e $\mathrm{Mg}$, e reduziu a saturação por alumínio. Ernani e Gianelo (1982), também trabalhando com esterco de poedeira, verificaram que ocorreu aumento na disponibilidade de nutrientes, bem como redução nos teores de alumínio trocável, o que contribuiu para o aumento da produção de matéria seca de aveia. Sherer et al. (apud CASSOL; GIANELLO; COSTA, 2001), analisando a resposta da cultura de milho a doses combinadas de superfosfato triplo e cama de frango, observaram que este esterco pôde substituir o adubo comercial como fonte de fósforo.

Além dos efeitos benéficos, existem estudos que indicam efeitos negativos associados à adição de resíduos orgânicos aos solos. Kiehl (1985) relatou que a aplicação de resíduos com alta relação carbono/ nitrogênio induzem a deficiência de nitrogênio às culturas. Dependendo da cultivar e do método de incorporação utilizado, os resíduos culturais de sorgo 
podem prejudicar o desenvolvimento da soja e o crescimento da biomassa microbiana do solo (VASCONSELOS et al., 1999). Em solos com pH elevado, aplicações anuais de altas doses de estercos, principalmente de aves podem facilitar o encrostamento, a desagregação das partículas pela chuva, reduzir a condutividade hidráulica, bem como favorecer a formação de substâncias cerosas repelentes à água, culminando com uma redução na sua capacidade de campo (ANDREOLA; COSTA; OLSZEVSKI, 2000).

Este trabalho teve como objetivo avaliar os efeitos, em médio prazo, da adição de diferentes adubos orgânicos sobre as propriedades químicas de um Latossolo Vermelho escuro distroférrico, do município de Londrina-PR.

\section{Materiais e Métodos}

O experimento foi instalado no ano de $2000 \mathrm{em}$ área de Latossolo Vermelho distroférrico (EMBRAPA, 1999) da Fazenda Escola da Universidade Estadual de Londrina, Londrina-PR, localizada a $23^{\circ} 23^{\prime}$ de latitude $S, 51^{\circ} 11^{\prime}$ de longitude W e 566 metros de altitude.

O delineamento utilizado foi de blocos casualizados, com seis tratamentos e três repetições. Cada parcela experimental foi constituída de um retângulo de $2 \mathrm{~m} \times 4 \mathrm{~m}$, onde foram aplicados os diferentes resíduos. Os tratamentos testados foram: TEST $=$ Testemunha $; \mathbf{E B}=$ Esterco de bovino $(8 \mathrm{~T}$ $\left.\mathrm{ha}^{-1}\right) ; \mathbf{E P}=$ Esterco de poedeira $\left(3 \mathrm{~T} \mathrm{ha}^{-1}\right) ; \mathbf{C F}=$ Cama de frango $\left(6 \mathrm{~T} \mathrm{ha}^{-1}\right) ; \mathbf{E O}=$ Esterco de ovino $\left(6 \mathrm{~T} \mathrm{ha}^{-1}\right)$; e $\mathbf{R S}=$ Resíduo de silagem $\left(8 \mathrm{~T} \mathrm{ha}^{-1}\right)$.

Os resíduos foram distribuídos homogeneamente na superfície de cada parcela e incorporados com o auxílio de enxada, à camada de $0-20 \mathrm{~cm}$ de profundidade. Aos três, seis, nove, doze, dezoito e vinte e quatro meses após a aplicação (maa), foram coletadas amostras do solo na camada superficial de 0-20 $\mathrm{cm}$ de profundidade, em três pontos de cada parcela, formando uma amostra composta. Todas amostras foram embaladas em sacos plásticos previamente identificados e encaminhadas para o laboratório de fertilidade de solos da UEL, onde foram adequadamente preparadas e submetidas a diferentes análises com a finalidade de avaliar as variações das propriedades químicas, determinadas pelos resíduos aplicados.

Cada amostra composta foi avaliada quimicamente, para as seguintes variáveis: $\mathrm{pH}$ em $\mathrm{CaCl}_{2}$ 0,01M, acidez potencial $(\mathrm{H}+\mathrm{Al})$, cálcio $(\mathrm{Ca})$, magnésio $(\mathrm{Mg})$ e potássio $(\mathrm{K})$ trocáveis, fósforo $(\mathrm{P})$ disponível e matéria orgânica (MO), conforme metodologia descrita por Pavan et al., (1992).

$\mathrm{O} \mathrm{Ca}$ e o $\mathrm{Mg}$ foram extraídos em $\mathrm{KCl} 1 \mathrm{M}$, titulando-se o extrato com EDTA-Na ${ }_{2}$ O K e o P foram extraídos com a solução extratora Mehlich-1. $\mathrm{Na}$ determinação do $\mathrm{K}$ foi utilizada a fotometria de chama, enquanto que, para o $\mathrm{P}$ foi utilizada a colorimetria.

A acidez potencial $(\mathrm{H}+\mathrm{Al})$ foi quantificada utilizando-se a solução tampão SMP. Para avaliação da matéria orgânica, empregou-se o método da oxidação por dicromato de potássio e titulação com sulfato ferroso (método Walkley \& Black). A partir dos resultados analíticos primários, foram calculadas a capacidade de troca catiônica (CTC pH 7,0) e a saturação por bases (V).

Os dados obtidos foram submetidos à análises de variância e as médias foram comparadas pelo teste Tukey a 1 e 5\% de significância.

\section{Resultados e Discussão}

Os valores médios de $\mathrm{pH}$, cálcio trocável $\left(\mathrm{Ca}^{++}\right)$ e acidez potencial $(\mathrm{H}+\mathrm{Al})$ do solo, obtidos no experimento, encontram-se na Tabela 1. 
Brito, O. R.; Vendrame, P. R. S; Brito, R. M.

Tabela 1. Valores médios para $\mathrm{pH}$ em $\mathrm{CaCl}_{2}$, Ca trocável $\left(\mathrm{cmolc} \mathrm{dm}^{-3}\right)$ e $\mathrm{H}+\mathrm{Al}\left(\mathrm{cmolc} \mathrm{dm}^{-3}\right)$ em função dos resíduos e épocas de avaliação (maa).*

\begin{tabular}{cccc|cccc}
\hline RESÍDUOS $^{\mathbf{1}}$ & $\mathbf{p H}$ & $\mathbf{C a}$ & $\mathbf{H}+\mathbf{A l}$ & $\mathbf{E ́ P O C A S}$ & $\mathbf{p H}$ & $\mathbf{C a}$ & $\mathbf{H}+\mathbf{A l}$ \\
\hline Test & $4,18 \mathrm{~A}$ & $3,30 \mathrm{~B}$ & $7,57 \mathrm{~B}$ & $\mathbf{3}$ & $4,30 \mathrm{~B}$ & $3,27 \mathrm{C}$ & $6,16 \mathrm{C}$ \\
EB & $3,83 \mathrm{~B}$ & $3,24 \mathrm{~B}$ & $8,35 \mathrm{AB}$ & $\mathbf{6}$ & $4,32 \mathrm{AB}$ & $3,51 \mathrm{BC}$ & $7,46 \mathrm{~B}$ \\
EP & $3,80 \mathrm{~B}$ & $3,14 \mathrm{~B}$ & $9,14 \mathrm{~A}$ & $\mathbf{9}$ & $3,61 \mathrm{C}$ & $3,79 \mathrm{~B}$ & $10,75 \mathrm{~A}$ \\
CF & $3,92 \mathrm{AB}$ & $3,38 \mathrm{~B}$ & $7,79 \mathrm{~B}$ & $\mathbf{1 2}$ & $3,26 \mathrm{D}$ & $3,25 \mathrm{C}$ & $10,51 \mathrm{~A}$ \\
EO & $4,04 \mathrm{AB}$ & $3,89 \mathrm{~A}$ & $8,37 \mathrm{AB}$ & $\mathbf{1 8}$ & $3,62 \mathrm{C}$ & $4,52 \mathrm{~A}$ & $7,64 \mathrm{~B}$ \\
RS & $4,00 \mathrm{AB}$ & $3,50 \mathrm{AB}$ & $8,07 \mathrm{AB}$ & $\mathbf{2 4}$ & $4,65 \mathrm{~A}$ & $2,11 \mathrm{D}$ & $6,78 \mathrm{BC}$ \\
\hline
\end{tabular}

${ }^{1}$ Test $=$ Testemunha, $\mathbf{E B}=$ esterco bovino, $\mathbf{E P}=$ esterco poedeira, $\mathbf{C F}=$ cama de frango, $\mathbf{E O}=$ esterco ovino, $\mathbf{R S}=$ resíduo silagem.

* Médias seguidas de mesma letra maiúscula nas colunas, não diferem entre si, pelo teste de Tukey a 1\%. maa = meses após aplicação

Em todos os tratamentos onde se aplicou resíduo orgânico, os valores de $\mathrm{pH}$ foram menores do que o da testemunha, porém, diferenças significativas só foram observadas para os tratamentos correspondentes a aplicação de esterco de bovino e esterco de poedeira, provavelmente devido a maior liberação de compostos nitrogenados e ácidos orgânicos, durante a decomposição. Quando se considerou a época de avaliação, os maiores valores foram encontrados para 24 meses, que apresentou valor semelhante ao observado na avaliação de 6 meses. Estes resultados contrariam os apresentados por Holanda; Mielniczuk e Stammel, (1982), que trabalharam com esterco de poedeira em uma seqüência de quatro culturas, e não observaram alterações no pH do solo.

O esterco de ovino foi o resíduo que determinou os maiores aumentos nos teores de cálcio do solo, porém não diferiu das parcelas tratadas com resíduo de silagem. Holanda; Mielniczuk e Stammel, (1982) também verificaram que a adição de esterco de poedeira (12 toneladas $\mathrm{ha}^{-1}$ ) aumentou significativamente os teores de cálcio no solo. Em relação as épocas de amostragem, os maiores e os menores valores foram verificados aos 18 e 24 meses, respectivamente (Tabela 1). Para a redução no teor de cálcio observada na ultima avaliação não há uma explicação lógica, uma vez que a área foi mantida com vegetação rasteira mediante roçagem. O menor valor observado na última avaliação, provavelmente está associado às variações espaciais na distribuição do cálcio no perfil do solo, determinadas pelo manejo anterior da área.

Em todos os tratamentos onde se aplicou resíduo orgânico, o valor da acidez potencial $(\mathrm{H}+\mathrm{Al})$ foi superior ao observado no tratamento testemunha. Entretanto, somente a aplicação de esterco de poedeira determinou aumento significativo (Tabela 1). Estes resultados se opõem aos observados por Ernani e Gianello (1983), que verificaram diminuição dos teores de alumínio trocável em função da adição de cama de frango (6 $\left.\mathrm{T} \mathrm{ha}^{-1}\right)$ e esterco de bovino (12 $\mathrm{T} \mathrm{ha}^{-1}$ ).

Quando se considerou o efeito das épocas de avaliação, os menores valores para $\mathrm{H}+\mathrm{Al}$, foram observados aos 3 e 24 meses, enquanto a máxima expressão foi observada entre 9 e 12 meses (Tabela 1). Estes resultados indicaram uma variação sazonal desta variável, possivelmente associada à atividade biológica do solo e à decomposição dos resíduos.

Os teores de magnésio do solo variaram em função dos tipos de resíduos e épocas de avaliação (Tabela 2). À exceção do tratamento com resíduo de silagem, não foram observadas variações bruscas dos teores deste nutriente no solo, mesmo quando o efeito dos tratamentos foi significativo. Entre os resíduos estudados, os estercos de bovino e ovino foram os que determinaram os maiores aumentos do teor de magnésio no solo. Na avaliação de 9 meses, 
observou-se que tanto a aplicação de cama de frango como a de esterco de poedeira, resultaram em reduções nos teores de magnésio do solo. Esses resultados estão de acordo com as observações de
Mello e Godofredo (2002), que também verificaram diminuição dos teores de magnésio em função da adição de cama de frango.

Tabela 2. Valores médios de magnésio, cálcio + magnésio, fósforo $(\mathrm{P})$ e potássio $(\mathrm{K})$ do solo, em função dos resíduos e das épocas de avaliação*:

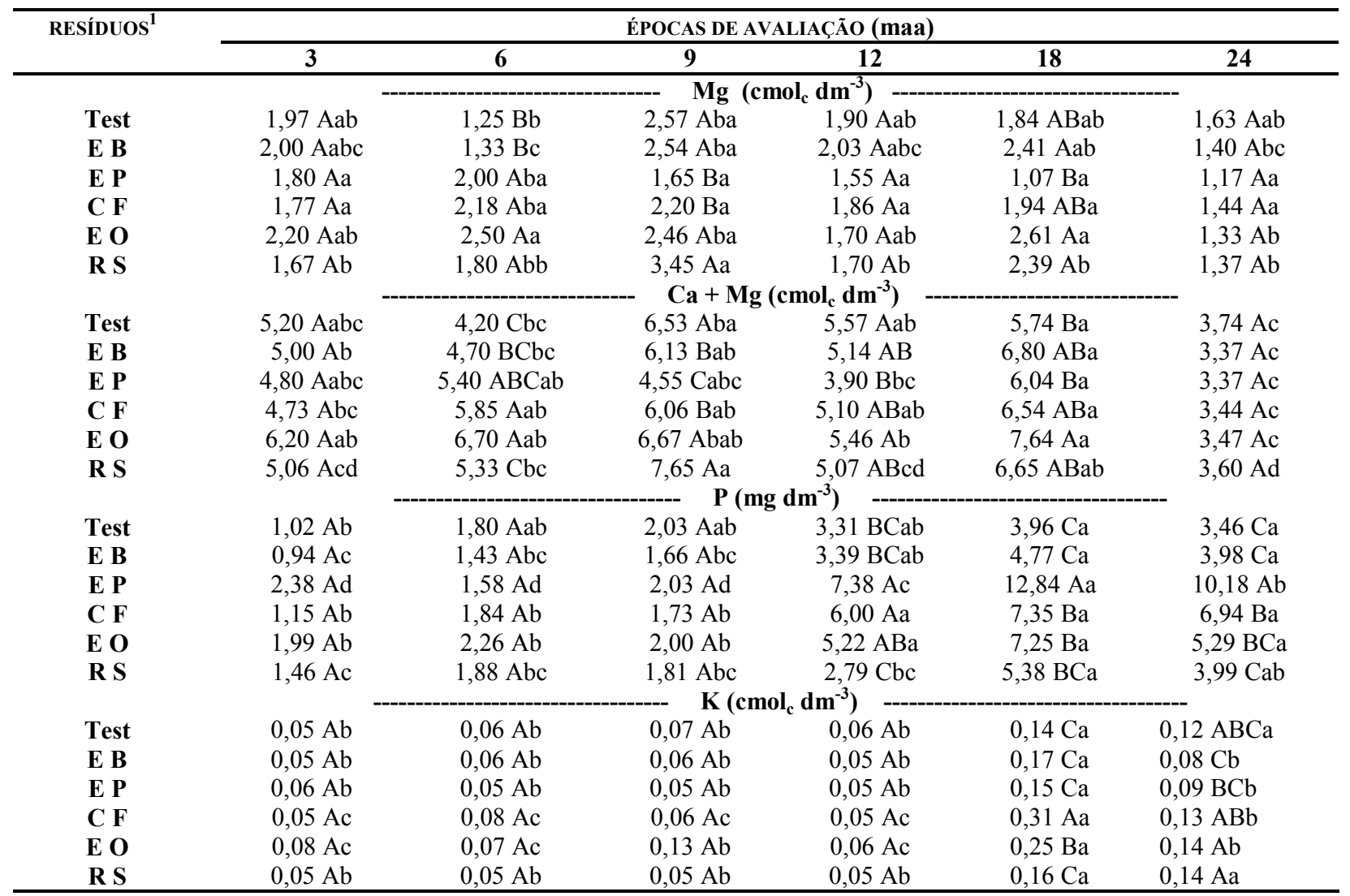

${ }^{1}$ Test $=$ Testemunha, $\mathbf{E B}=$ esterco bovino, $\mathbf{E P}=$ esterco poedeira, $\mathbf{C F}=$ cama de frango, $\mathbf{E} \mathbf{O}=$ esterco ovino, $\mathbf{R S}=$ resíduo silagem. * Médias seguidas de mesma letra maiúscula nas colunas e minúscula nas linhas, não diferem entre si, pelo teste de Tukey a $1 \%$ de probabilidade. maa =meses após aplicação

$\mathrm{Na}$ avaliação conjunta de cálcio + magnésio (Tabela 2), observou-se que para todos os resíduos o efeito de época foi significativo. Os maiores valores médios foram observados nas avaliações de 9 e 18 meses nos tratamentos correspondentes à aplicação de resíduo de silagem e esterco de ovino, respectivamente. $\mathrm{O}$ uso da cama de frango resultou em aumentos significativos dos teores de $\mathrm{Ca}+\mathrm{Mg}$ nas avaliações de 6 e 18 meses, resultados que estão em acordo com os observados por Gianello e Ernani (1983).
Os teores de fósforo e potássio do solo só foram alterados significativamente pelos resíduos testados nas últimas avaliações (Tabela 2). Para o fósforo, nas avaliações de 18 e 24, o esterco de poedeira foi o resíduo que determinou os maiores aumentos deste nutriente, diferindo dos demais. Gianello e Ernani (1983) trabalhando com doses crescentes de cama de frango, verificaram aumento dos teores de fósforo extraível com o aumento das doses do referido esterco. Para Gillis et al., citado por Cassol; Gianello e Costa (2001), os estercos de aves (cama de frango 
e de poedeira) podem contribuir para o aumento do teor de fósforo do solo, pois grande parte do fósforo adicionado na ração não é hidrolisada pelo sistema digestivo das aves, sendo então liberado nas fezes ou estercos.

Aumentos significativos dos teores de potássio do solo foram observados nas avaliações de 18 meses, principalmente nas parcelas que receberam aplicação de cama de frango e esterco de ovino (Tabela 2). Estes aumentos, podem ter ocorrido em razão do efeito cumulativo, uma vez que a segunda aplicação dos resíduos foi feita após a coleta de amostras para avaliação dos 12 meses.
Em relação à matéria orgânica (Tabela 3), o esterco de ovino foi o resíduo que proporcionou os maiores teores ao longo das avaliações, porém os valores encontrados não diferiram significativamente da testemunha. Resultados semelhantes foram observados por Ernani e Gianello (1983), que verificaram que os teores de matéria orgânica não foram alterados pela adição de esterco de galinha e esterco de bovino. Quanto às épocas de avaliação, observou-se que os maiores teores de matéria orgânica do solo foram obtidos na avaliação dos 24 meses, que diferiu significativamente das demais. Pode-se atribuir este aumento ao efeito cumulativo da segunda aplicação dos resíduos.

Tabela 3. Valores médios para matéria orgânica (MO), CTC e saturação por bases (V), em função dos resíduos e épocas de avaliação (maa).*

\begin{tabular}{cccc|cccc}
\hline RESÍDUOS $^{1}$ & M O & CTC & V\% & ÉPOCAS & M.O. & CTC & V\% \\
\hline Test & $19,83 \mathrm{AB}$ & $12,81 \mathrm{~B}$ & $39,83 \mathrm{AB}$ & $\mathbf{3}$ & $14,90 \mathrm{D}$ & $11,05 \mathrm{E}$ & $45,90 \mathrm{~A}$ \\
EB & $20,05 \mathrm{AB}$ & $13,62 \mathrm{AB}$ & $38,86 \mathrm{AB}$ & $\mathbf{6}$ & $20,70 \mathrm{~B}$ & $12,89 \mathrm{D}$ & $42,07 \mathrm{AB}$ \\
EP & $19,45 \mathrm{~B}$ & $13,72 \mathrm{AB}$ & $35,53 \mathrm{~B}$ & $\mathbf{9}$ & $17,58 \mathrm{C}$ & $17,09 \mathrm{~A}$ & $37,04 \mathrm{BC}$ \\
CF & $20,21 \mathrm{AB}$ & $13,19 \mathrm{~B}$ & $41,06 \mathrm{AB}$ & $\mathbf{1 2}$ & $20,55 \mathrm{~B}$ & $15,60 \mathrm{~B}$ & $32,84 \mathrm{C}$ \\
EO & $22,33 \mathrm{~A}$ & $14,35 \mathrm{~A}$ & $42,96 \mathrm{~A}$ & $\mathbf{1 8}$ & $18,36 \mathrm{BC}$ & $14,40 \mathrm{C}$ & $46,87 \mathrm{~A}$ \\
RS & $20,42 \mathrm{AB}$ & $13,72 \mathrm{AB}$ & $41,50 \mathrm{~A}$ & $\mathbf{2 4}$ & $30,23 \mathrm{~A}$ & $10,38 \mathrm{E}$ & $35,00 \mathrm{C}$ \\
\hline
\end{tabular}

${ }^{1}$ Test $=$ Testemunha, $\mathbf{E B}=$ esterco bovino, $\mathbf{E P}=$ esterco poedeira, $\mathbf{C F}=$ cama de frango, $\mathbf{E O}=$ esterco ovino, $\mathbf{R S}=$ resíduo silagem. * Médias seguidas de mesma letra maiúscula nas colunas e minúscula nas linhas, não diferem entre si, pelo teste de Tukey a $1 \%$ de probabilidade. maa = meses após aplicação.

Todos os resíduos orgânicos testados aumentaram os valores médios da CTC em relação à testemunha, porém, diferença significativa só foi observada no tratamento com esterco de ovino (Tabela 3). O pequeno acréscimo nos valores da CTC, ocasionado pelos outros resíduos, podem estar ligados às doses utilizadas no experimento, pois, Gianello e Ernani (1983), trabalhando com doses de até $144 \mathrm{t} \mathrm{ha}^{-1}$, verificaram aumentos crescentes dos valores da CTC. Entre as épocas de avaliação, foi aos 9 meses que se verificou o maior valor para CTC, diferindo significativamente das demais. Associadas às alterações da CTC ocorreram também modificações na saturação por bases (V). Neste caso verificou-se que o esterco de poedeira resultou no menor valor de $\mathrm{V}$, diferindo do esterco de ovino e do resíduo de silagem.
Quando se considerou a época de avaliação, os maiores valores de (V) foram verificados aos 3, 6 e 18 meses, diferindo significativamente das demais avaliações.

\section{Conclusões}

A aplicação de diferentes resíduos orgânicos resultou em alterações significativas das propriedades químicas e fertilidade do solo.

Para as doses estudadas, o esterco de ovino foi o resíduo que determinou as principais alterações das propriedades químicas do solo, uma vez que em relação à testemunha, promoveu os maiores aumentos para cálcio, matéria orgânica e capacidade de troca de cátions. 
O esterco de poedeira, após uma segunda aplicação, resultou em aumento significativo dos teores de fósforo do solo.

\section{Referência}

ANDREOLA, F.; COSTA, L. M.; OLSZEVSKI, N. Influência da cobertura vegetal de inverno e da adubação orgânica e, ou, mineral sobre as propriedades físicas de uma terra roxa estruturada. Revista Brasileira de Ciência Do Solo, Campinas, v. 24, p. 857-865, 2000.

BRADY, N. C. Natureza e propriedade dos solos. Rio de Janeiro: Freitas Bastos, 1989. 878p.

CASSOL, P. C; GIANELLO, C.; COSTA, V.E. U. Fração de fósforo em estrumes e sua eficiência como adubo fosfatado. Revista Brasileira de Ciência do Solo, Campinas, v. 25, p. 636-644, 2001.

DURIGON, R.; CERETTA, C. A.; BASSO, C. J.; BARCELLOS, L. A. R.; PAVINATO, P. S. Produção de forragem em pastagem natural com o uso de esterco líquido de suínos. Revista Brasileira de Ciência do Solo, Campinas, v. 26, p. 983-992, 2002.

ERNANI, P. R.; GIANELLO, C. Efeito imediato e residual de materiais orgânicos, adubo mineral e calcário no rendimento vegetal. Revista Brasileira de Ciência do Solo, Campinas, v. 6, p. 119-124, 1982.

ERNANI, P. R.; GIANELLO, C. Diminuição do alumínio trocável do solo pela incorporação de esterco de bovinos e camas de aviário. Revista Brasileira de Ciência do Solo, Campinas, v. 7, p. 161-165, 1983.
GIANELLO, C.; ERNANI, P. R. Rendimento de matéria seca de milho e alterações na composição química do solo pela incorporação de quantidades crescentes de cama de frangos, em casa de vegetação. Revista Brasileira de Ciência do Solo, Campinas, v. 7, p. 285-290, 1983.

HOLANDA, J. S.; MIELNICZUK, J.; STAMMEL, J. G. Utilização de esterco e adubo mineral em quatro seqüências de culturas em solo de encosta basáltica do Rio Grande do Sul. Revista Brasileira de Ciência do Solo, Campinas, v. 6, p. 47-51, 1982.

IGUE, K. Dinâmica da matéria orgânica e seus efeitos nas propriedades do solo. In: FUNDAÇÃO CARGILL. Adubação Verde no Brasil. Campinas, 1984. p. 232-267.

KIEHL, E. J. Fertilizantes orgânicos. São Paulo: Ceres, 1985. 492p.

MALAVOLTA, E.; PIMENTEL-GOMES, F.; ALCARDE, J. C. Adubos e Adubações. São Paulo: Nobel, 2002. 200p.

MELLO, S. C.; GODOFREDO, C. Desenvolvimento do tomateiro e modificações nas propriedades químicas do solo em função da aplicação de resíduos orgânicos, sob cultivo protegido. Horticultura Brasileira, Brasília, v. 20, n. 2, p. 200-206, 2002.

PAVAN, M. A.; BLOCH, M. F.; ZEMPULSKI, H. C.; MIYAZAWA, M.; ZOCCOLER, D. C. Manual de análise química de solo e controle de qualidade. Londrina: IAPAR, 1992. 40p. (Circular 76).

RAIJ, B. V. Fertilidade do solo e adubação. Piracicaba: Ceres- Potafos, 1991.343p.

VASCONSELOS, C. A.; CAMPOLINA, D. C. A.; SANTOS, F. G.; PITTA, G. V. E.; MARRIEL, J. E. Resposta da soja e da biomassa de carbono do solo aos resíduos de cinco genótipos de sorgo. Revista Brasileira de Ciência do Solo, Campinas, v. 23, p. 70-77, 1999. 